\title{
latrogenic Bile Duct Injury and Its Management with Intensive Care Unit Process: A Single-Center Experience
}

\author{
Ibrahim Mungan ${ }^{*}$, Sema Turan ${ }^{1}$, Büsra Tezcan ${ }^{1}$, Bahar Aydınlı , Erdal Birol Bostancl ${ }^{3}$ and Bulent \\ Odemis $^{4}$
}

${ }^{1}$ Department of Intensive Care Unit, Ankara Şehir Hastanesi, Turkey

${ }^{2}$ Department of Anesthesiology and Reanimation, Mersin Şehir Hastanesi, Turkey

${ }^{3}$ Department of Gastroenterological Surgery, Ankara Şehir Hastanesi, Turkey

${ }^{4}$ Department of Gastroenterology, Ankara Şehir Hastanesi, Turkey

\begin{abstract}
Background: The delayed recognition of bile duct injury (BDI) and the challenges in its diagnosis lead to clinical variability. The management of BDI is complicated and ranges from ERCP to liver transplantation. But infections related to $\mathrm{BDI}$ and sepsis control, prior to the bile flow reestablishment, are the mainstay of the treatment. In this study, we aimed to report the clinical outcomes of iatrogenic BDI and intensive care unit (ICU) process in a tertiary state hospital.

Materials and methods: In this single-center, retrospective, cohort study, 17 patients admitted to our hospital with BDI after LC or ERCP were enrolled from January 2016 to July 2018. The outcomes of BDI were assessed only in short term period-as long as the length of hospital stay-and the statistical analysis was performed using SPSS version 20.0 for Windows (SPSS Inc., Chicago, IL, USA). Statistical significance was determined by a $p$ value less than 0.05 .

Results: Throughout the study period, the patients with BDI were referred mostly after $L C(n=14,82.4 \%)$. The mean age was 52.5 years and 14 of these patients were referred us from another hospital. $94.1 \%$ of the patients admitted to ICU in the first week after injury and the main symptom in the admission was right quadrant pain. Surgery was required only in seven cases $(41.2 \%)$ and the in-hospital mortality rate was $17.6 \%(n=3)$. It was clearly shown that mortality and sepsis relation was significant statistically $(p<0.001)$ whereas delayed admission was not related to morbidity or mortality statistically.

Discussion: The rate of BDI after LC or ERCP varies and the challenge in the diagnosis of BDI is that they are not recognized at the time of LC or ERCP in the majority of cases. The identification of sepsis in the early phase leads to proper management of BDI while the morbidity and mortality rates are increasing in cases of major BDI, delayed referral and sepsis involvement. In our study, the in-hospital mortality rate was higher than the mortality rate related to BDI (17.2\% vs. $7.2 \%)$ in the literature. There are many studies comparing surgical techniques and the timing of the definitive treatment while endoscopic methods have become more preferable than surgery in the early phase of BDI.

Conclusion: In conclusion, early recognition of BDI after LC or ERCP is essential and the management of this feared complication requires a multidisciplinary approach with the contribution of a surgeon, gastroenterologist, and intensivist.
\end{abstract}

\section{Keywords}

Bile duct Injury, latrogenic, Mortality, Sepsis, Intensive care

\section{Background}

Laparoscopic cholecystectomy (LC), which becomes the standard of care for symptomatic cholelithiasis, and endoscopic retrograde cholangiopancreatography (ERCP), the gold standard diagnostic pathway for biliary disease, may lead to serious complications like bile duct injury (BDI). latrogenic bile duct injury after $\mathrm{LC}$ was reported at $0.3 \%$ to $2.6 \%$ interval and approximately $80 \%$ of patients with BDI underwent definitive surgery [1]. In fact, approximately
*Corresponding author: Ibrahim Mungan, MD, Department of Intensive Care Unit, Ankara Şehir Hastanesi, Bilkent/Ankara, Turkey, Tel: +90-5075081594

Accepted: September 27, 2019

Published online: September 29, 2019

Citation: Mungan I, Turan S, Tezcan B, et al. (2019) latrogenic Bile Duct Injury and Its Management with Intensive Care Unit Process: A Single-Center Experience. Insights Biomed Res 3(1):68-71

Copyright: (C) 2019 Mungan I, et al. This is an open-access article distributed under the terms of the Creative Commons Attribution License, which permits unrestricted use, distribution, and reproduction in any medium, provided the original author and source are credited. 
Citation: Mungan I, Turan S, Tezcan B, et al. (2019) latrogenic Bile Duct Injury and Its Management with Intensive Care Unit Process: A SingleCenter Experience. Insights Biomed Res 3(1):68-71

$70 \%$ of the transection of the common bile duct (CBD) and true partial injury may be recognized and repaired during the surgery or ERCP [2]. Delayed recognition and the challenges in the diagnosis of BDI lead to clinical variability from mild tenderness and asymptomatic abdominal pain to the life-threatening complications like septic shock at presentation [3].

The management of BDI is also complicated and ranges from nonsurgical interventions like ERCP to liver transplantation. But infections related to BDI and sepsis control, prior to the bile flow reestablishment, is the mainstay of the treatment [1]. More recently ERCP becomes one of the definitive treatment modality among with surgery and percutaneous transhepatic cholangiography (PTC). Especially in cases of bile leak without transection ERCP was found adequate for definitive treatment [4]. The ERCP intervention includes ERCP, sphincterotomy, and stenting while the surgical options for BDI are simple repair, End-to-end bile duct anastomosis, Roux-en-Y biliary enteric anastomosis and partial hepatectomy [3]. Although the advancements in surgery, gastroenterology and intensive care ameliorate the outcomes of BDI, the mortality and morbidity rates are still high [5]. In this study, we aimed to report the clinical outcomes of iatrogenic BDI and intensive care unit (ICU) process in a tertiary state hospital.

\section{Material and Method}

In this single-center, retrospective, cohort study, 17 patients admitted to our hospital with BDI after LC or ERCP were enrolled from January 1,2016 , to July 31,2018 . Patient characteristics, details of BDI, and hospital courses were derived from the hospital database and patients' medical records. The patients with BDI presented to our intensive care unit either as acute bile duct injury (before $48 \mathrm{~h}$ ) or as delayed (after 48 h) injury, and BDI were classified according to Bismuth-Strasberg Classification [6]. The patients with BDI after PTC, trauma or surgical operations other than LC were excluded. The outcomes of BDI were assessed only in short term period-as long as the length of hospital stay-because the data about long-term outcomes could not be derived from the hospital database.

Statistical analysis was performed using SPSS version 20.0 for Windows (SPSS Inc., Chicago, IL, USA). Since the number of patients included in this study was small and the variables did not show a normal distribution in Kolmogorov-Smirnov test, the variables were evaluated by nonparametric tests. The correlation between variables was assessed with Spearman Rho Correlation Coefficient test, and the Mann-Whitney $U$ test was used for categorical variables. Statistical significance was determined by a $p$ value less than 0.05 .

An extra formal consent other than the patients had given prior to the admission to as a routine procedure, was not required for the current study because it was a case-control medical record review. This study adhered to the principles in accordance with the Helsinki Declaration of 1975, as revised in 2008.

\section{Results}

Throughout the study period, 17 patients with BDI were managed in our institution and they were referred mostly after LC ( $n=14,82.4 \%)$. Nine of the patients were males and eight of them were females. The mean age was 52.5 years (minimum 23 and maximum 87 years). 14 of these

Table 1: The demographic variables and data related to hospital admission.

\begin{tabular}{|c|c|c|c|c|}
\hline \multicolumn{3}{|l|}{ Variable } & $\begin{array}{l}\text { Frequency/ } \\
\text { mean }\end{array}$ & $\begin{array}{l}\text { Percent/ } \\
\text { SD }\end{array}$ \\
\hline \multicolumn{3}{|l|}{ Male gender } & 9 & $52.9 \%$ \\
\hline \multicolumn{3}{|c|}{ Female gender } & 8 & $47.1 \%$ \\
\hline \multirow{3}{*}{$\begin{array}{l}\text { Reason for } \\
\text { admission }\end{array}$} & \multicolumn{2}{|c|}{ Right quadrant pain } & 13 & $76.5 \%$ \\
\hline & \multicolumn{2}{|c|}{ Fever } & 2 & $11.8 \%$ \\
\hline & \multicolumn{2}{|c|}{ Acute abdomen } & 2 & $11.8 \%$ \\
\hline \multicolumn{3}{|c|}{ Out hospital admission } & 14 & $82.4 \%$ \\
\hline \multicolumn{3}{|c|}{ In-hospital admission } & 3 & $17.6 \%$ \\
\hline \multirow{2}{*}{\multicolumn{2}{|c|}{ Cause of BDI }} & LC & 14 & $82.4 \%$ \\
\hline & & ERCP & 3 & $17.6 \%$ \\
\hline \multicolumn{3}{|c|}{ Delayed admission/referral } & 5 & $29.4 \%$ \\
\hline \multicolumn{3}{|c|}{ Acute admission/referral } & 12 & $70.6 \%$ \\
\hline \multicolumn{3}{|l|}{ Age } & 52.5 & \pm 19.6 \\
\hline \multirow{7}{*}{\multicolumn{2}{|c|}{$\begin{array}{l}\text { Bismuth-Strasberg } \\
\text { classification }\end{array}$}} & $A$ & 5 & $29.4 \%$ \\
\hline & & B & 0 & 0 \\
\hline & & C & 1 & $5.9 \%$ \\
\hline & & $\mathrm{D}$ & 2 & $11.8 \%$ \\
\hline & & E1 & 3 & $17.6 \%$ \\
\hline & & E2 & 3 & $17.6 \%$ \\
\hline & & E3 & 3 & $17.6 \%$ \\
\hline \multirow{2}{*}{\multicolumn{2}{|c|}{ Management }} & $\begin{array}{l}\text { ERCP and } \\
\text { stenting }\end{array}$ & 10 & $58.8 \%$ \\
\hline & & $\begin{array}{l}\text { Surgical } \\
\text { intervention }\end{array}$ & 7 & $41.2 \%$ \\
\hline \multirow{4}{*}{\multicolumn{2}{|c|}{ Surgical method }} & $\begin{array}{l}\text { Choledocotomy } \\
\text { and primary } \\
\text { repair on T tube }\end{array}$ & 4 & $23.5 \%$ \\
\hline & & $\begin{array}{l}\text { Roux-en-Y } \\
\text { hepatico- } \\
\text { jejunostomy }\end{array}$ & 2 & $11.8 \%$ \\
\hline & & $\begin{array}{l}\text { Hepp-Couinaud } \\
\text { approach }\end{array}$ & 1 & $5.9 \%$ \\
\hline & & No surgery & 10 & $58.8 \%$ \\
\hline \multicolumn{3}{|l|}{ Mortality } & 3 & $17.6 \%$ \\
\hline \multicolumn{3}{|l|}{ Complication } & 4 & $23.50 \%$ \\
\hline \multicolumn{3}{|l|}{ Septic shock } & 2 & $11.8 \%$ \\
\hline \multicolumn{3}{|c|}{ No complication } & 12 & $70.6 \%$ \\
\hline
\end{tabular}

Abbreviations: SD: Standard Deviation; BDI: Bile Duct Injury; LC: Laparoscopic Cholecystectomy; ERCP: Endoscopic Retrograde Cholangiopancreatography; BDI were classified according to Bismuth-Strasberg Classification (6) from A to $E$. 
Citation: Mungan I, Turan S, Tezcan B, et al. (2019) latrogenic Bile Duct Injury and Its Management with Intensive Care Unit Process: A SingleCenter Experience. Insights Biomed Res 3(1):68-71

Table 2: The variables and outcomes of BDI, and their relations with sepsis and delayed admission factor.

\begin{tabular}{|c|c|c|c|c|c|c|}
\hline Variable & Septic shock $(+)(n=2)$ & $\begin{array}{l}\text { Septic shock }(-) \\
(\mathrm{n}=15)\end{array}$ & $\begin{array}{l}\text { Delayed } \\
\text { admission }(n=5)\end{array}$ & Total $(n=17)$ & $\mathrm{p}^{*}$ & $\mathbf{p}^{+}$ \\
\hline Male gender & $1(50 \%)$ & $8(53.3 \%)$ & $3(60 \%)$ & $9(52.9 \%)$ & 0.935 & 0.728 \\
\hline Acute abdomen & 0 & $2(13.3 \%)$ & 0 & $2(11.8 \%)$ & 0.16 & 0.498 \\
\hline Out hospital admission & $2(100 \%)$ & $12(80 \%)$ & $5(100 \%)$ & $14(82.4 \%)$ & 0.517 & 0.244 \\
\hline After LC & $1(50 \%)$ & $13(86.7 \%)$ & $4(80 \%)$ & $14(82.4 \%)$ & 0.226 & 0.879 \\
\hline Surgery & $2(100 \%)$ & $5(33.3 \%)$ & $3(60 \%)$ & $7(41.2 \%)$ & 0.080 & 0.20 \\
\hline Mortality & $2(100 \%)$ & $1(6.7 \%)$ & 2 (40\%) & $3(17.6 \%)$ & $<0.001$ & 0.134 \\
\hline Complication & $2(100 \%)$ & $2(13.3 \%)$ & $3(60 \%)$ & $4(23.5 \%)$ & 0.04 & 0.082 \\
\hline Noticed in the first week & $2(100 \%)$ & $14(93.3 \%)$ & NA & $16(94.1 \%)$ & 0.03 & NA \\
\hline Age (years) & $71.5 \pm 13.4$ & $50 \pm 19.2$ & $48.6 \pm 23.2$ & $52.5 \pm 19.6$ & 0.017 & 0.598 \\
\hline LOS hospital (days) & $25 \pm 29.6$ & $17.2 \pm 18.7$ & $27.4 \pm 24$ & $18.1 \pm 19.2$ & 0.613 & 0.291 \\
\hline LOS ICU(days) & $25 \pm 29.6$ & $10.8 \pm 13.3$ & $18.2 \pm 16.7$ & $12.4 \pm 15.2$ & 0.160 & 0.134 \\
\hline
\end{tabular}

The variables were presented either as mean \pm SD or frequency and percentage.

"The relations between variables and outcomes were calculated for "septic shock" factor.

${ }^{*}$ The relations between variables and outcomes were calculated for "delayed admission" factor.

Abbreviations: SD: Standard deviation; BDI: Bile Duct Injury; LC: Laparoscopic Cholecystectomy; LOS: Length of Stay; ICU: Intensive Care Unit; NA: Not Applicable.

patients were referred us from another hospital and only $17.6 \%$ of cases sustained BDI in our institution. The demographic variables and data related to hospital admission were summarized in Table 1 and $94.1 \%$ of the patients admitted to ICU in the first week after injury. $70.6 \%$ of patients were classified as acute $(n=12)$ and $29.4 \%$ of them were classified as delayed admission. The main symptom in the admission was right quadrant pain.

Surgery was required only in seven cases $(41.2 \%)$ and the in-hospital mortality rate was $17.6 \%(n=3)$. The length of stay (LOS) in hospital and in ICU was 18.12 and 12.47 days respectively as mentioned in results Table 2 . Table 2 summarizes the outcomes and their relations with sepsis and delayed admission. It is clearly shown that mortality and sepsis relation was significant statistically $(p<0.001)$ whereas delayed admission was not related to morbidity or mortality statistically.

\section{Discussion}

The rate of $\mathrm{BDI}$ after $\mathrm{LC}$ or $\mathrm{ERCP}$ varies between $0.3 \%$ and $2.6 \%$ in the literature [1] while major $\mathrm{BDI}$ was reported as low as $0.08 \%[7,8]$. In a recent review, it was reported that the majority of the BDI cases after LC were Strasberg type A injury (about 83\%) and managed with ERCP successfully [1]. In this review, the definitive treatment of Strasberg type $D$ injuries was reported as ERCP and stenting in $75 \%$ of cases. Even in extreme cases of CBD complete transection without tissue defect ERCP and PTC combination was used due to high operative risks and the outcomes were defined as good [9].

The challenge in the diagnosis of BDI is that they are not recognized at the time of LC or ERCP in a majority of cases (as high as $80 \%$ ) and the presentation after interventions can be covert by nonspecific symptoms [10]. This mandates the clinicians and the intensivists to be suspicious about the risk of BDI. The identification of the biliary peritonitis and sepsis in the early phase lead to proper management of BDI while the morbidity and mortality rates are increasing in cases of major BDI, delayed referral and sepsis involvement $[11,12]$.

Schreuder, et al. [7] claimed that delayed referral after BDI was related to increased morbidity and in our study delayed admission group had longer LOS in ICU and in-hospital (27.4 days vs. 14.2 and 18.2 days vs. 10.1 days respectively). Although this difference in our study was not significant statistically $(p>0.05)$ it was in line with Martinez-Lopez, et al. study [13] in which the relation between longer LOS in hospital and delayed referral was shown.

In our study, the in-hospital mortality rate was higher than the mortality rate related to $\mathrm{BDI}(17.2 \%$ vs. $7.2 \%)$ in the literature [1]. This is probably due to the deteriorating effect of sepsis and septic shock which was detected in $66 \%$ of mortal cases in our study. Also, the majority of cases $(n=9,52.8 \%)$ in our study was presented with Strasberg type $\mathrm{E}$ injuries unlike the literature and this factor might affect the mortality rate.

There are many studies comparing surgical techniques for $\mathrm{BDI}$ as a definitive management modality $[1,11,12]$. The timing of the definitive treatment (either in the early phase or after controlling the sepsis and bile leak) is another disputable issue although endoscopic methods have become more preferable than surgery in the early phase of BDI $[4,10]$. Sendino, et al. [14] claimed that endoscopic methods like ERCP and stenting could be utilized for BDI even after liver transplantation.

\section{Conclusion}

In conclusion, early recognition of BDI after LC or ERCP is essential and the management of this feared complication re- 
quires a multidisciplinary approach with the contribution of a surgeon, gastroenterologist, and intensivist.

\section{Limitations}

The limitations related to this study were the retrospective nature of this analysis, the small number of patients and the limited data derived from the database of our institution.

\section{Declarations}

\section{Ethics approval and consent to participate}

Since our study was in the category of non-interventional clinical research with its retrospective structure, the need for ethical approval was waived. This is in line with the National Code of Clinical Research which is recently published on $13^{\text {th }}$ April 2013.

This study adhered to the principles in accordance with the Helsinki Declaration of 1975, as revised in 2008. An extra formal consent other than the one which was taken prior to hospitalization was not required for the current study because of the non-interventional, retrospective design. It was a case-control medical record review.

\section{Consent to publish}

Not applicable.

\section{Availability of data and materials}

The datasets during the current study available from the corresponding author on reasonable request.

\section{Competing interests}

The authors declare that they have no competing interests.

\section{Funding}

No funding was received.

\section{Acknowledgements}

Not applicable.

\section{Disclosures}

None.

\section{References}

1. Cohen JT, Charpentier KP, Beard RE (2019) An update on iatrogenic biliary injuries: Identification, classification, and management. Surg Clin North Am 99: 283-299.

2. Barrett M, Asbun HJ, Chien HL, et al. (2017) Bile duct injury and morbidity following cholecystectomy: A need for improvement. Surg Endosc 32: 1683-1688.

3. Kohn JF, Trenk A, Kuchta K, et al. (2018) Characterization of common bile duct injury after laparoscopic cholecystectomy in a high-volume hospital system. Surg Endosc 32: 1184-1191.

4. Mishra PK, Saluja SS, Nayeem M, et al. (2015) Bile duct injuryfrom injury to repair: An analysis of management and outcome. Indian J Surg 77: 536-542.

5. Antonio Pesce, Stefano Palmucci, Gaetano La Greca, et al. (2019) latrogenic bile duct injury: Impact and management challenges. Clin Exp Gastroenterol 12: 121-128.

6. Strasberg SM, Hertl M, Soper NJ (1995) An analysis of the problem of biliary injury during laparoscopic cholecystectomy. J Am Coll Surg 180: 101-125.

7. Schreuder AM, Busch OR, Besselink MG, et al. (2019) Long-term impact of iatrogenic bile duct injury. Dig Surg 1-12.

8. Halbert C, Altieri MS, Yang J, et al. (2016) Long-term outcomes of patients with common bile duct injury following laparoscopic cholecystectomy. Surg Endosc 30: 4294-4299.

9. Lindemann J, Kloppers C, Burmeister S, et al. (2019) Mind the gap! Extraluminal percutaneous-endoscopic rendezvous with a self-expanding metal stent for restoring continuity in major bile duct injury: A case series. Int J Surg Case Rep 60: 340-344.

10. Eum YO, Park JK, Chun J, et al. (2014) Non-surgical treatment of post-surgical bile duct injury: Clinical implications and outcomes. World J Gastroenterol 20: 6924-6931.

11. Kirks RC, Barnes TE, Lorimer PD, et al. (2016) Comparing early and delayed repair of common bile duct injury to identify clinical drivers of outcome and morbidity. HPB 18: 718-725.

12. Gupta V, Gupta A, Yadav TD, et al. (2019) Post-cholecystectomy acute injury: What can go wrong? Ann Hepatobiliary Pancreat Surg 23: 138-144.

13. Martinez-Lopez S, Upasani V, Panaboyana S, et al. (2017) Delayed referral to specialist centre increases morbidity in patients with bile duct injury (BDI) after laparoscopic cholecystectomy (LC). Int J Surg 44: 82-86.

14. Sendino O, Fernández-Simon A, Law R, et al. (2018) Endoscopic management of bile leaks after liver transplantation: An analysis of two high-volume transplant centers. United European Gastroenterol J 6: 89-96.

DOI: $10.36959 / 584 / 449$

Copyright: (C) 2019 Mungan I, et al. This is an open-access article distributed under the terms of the Creative Commons Attribution License, which permits unrestricted use, distribution, and reproduction in any medium, provided the original author and source are credited. 